\title{
Chinese Literary Logic: Imaginary Thinking in Cognitive Structure*
}

\author{
Lei Jia \\ Department of Basic Subjects \\ Xinjiang Police College \\ Urumqi, China
}

\author{
Xiaomang Zhang \\ School of Philosophy \\ Nankai University \\ Tianjin, China
}

\begin{abstract}
Chinese characters are ideographic writing, and there is a close relationship between their physical structures and meanings. The logic-cognitive process of this connection is determined by the normative role of traditional Chinese imagery thinking. In the logic-cognitive process of visual analogy, it regulates the historical process of the development of Chinese characters and guides the Chinese people's aesthetic concepts and methods in the process of literacy recognition by adopting a thinking method that combines subjective will and external objects. To taste the normative function of this mode of thinking, it's better to appreciate its underlying principles of logical methodology, aesthetic concepts, technical methods, cultural traditions and humanistic spirit.
\end{abstract}

Keywords-Chinese characters; imagery thinking; logiccognition

\section{INTRODUCTION}

As a symbol of recording natural language, Chinese characters are ideographic words. There is a close relationship between their physical structures and meanings. To understand the logical-cognitive process from "real image" to "mental image" is to recognize the cultural tradition of the stable imagery thinking mode behind it.

\section{THE NORMATIVE ROLE OF IMAGERY THINKING IN THE PROCESS OF CHINESE CHARACTER CREATION}

Mr. Chen Yinke once said, "Every explanation of a word means making research on a history of culture". This is because the emergence and development of Chinese characters is a process of character-making called "six categories of Chinese characters (hieroglyphic, self-explanatory characters, understanding, echoism, mutually explanatory or synonymous characters, borrowing)" by the ancients. In this historical process, there is always a stable cultural tradition that influences the way of national thinking. As a way of thinking that integrates subjective wishes and external images, imagery thinking regulates the historical process of ancient Chinese characters' development with its logical-cognitive approach of visual analogy, and guides the aesthetic concepts and methods

*Fund projects: The State Major Social Science Foundation Project Subtopic "A study on Tibetan Folk Literature and Gesar's Rap Art arrangement \& Protection and inheritance " of "Arrangement, inheritance and Digital Conservation of Tibet's Intangible Cultural Heritage (13\&ZD141)". of ancient Chinese in the process of character-making.

Based on Hegel, "according to the order of time, the consciousness of human beings always forms the representation of the object before forming the concept, and only through the representation can the mind of human beings realize and grasp the thinking of things" ${ }^{1}$, which is in line with the concept of Cangjie, an official historian of Yellow Emperor that "realizing the difference of birds texture and that of beasts after he seeing the footprints of these two kind of creatures and so he began to create characters. In response, there were definite undertakings and various kinds of characters." On the basis of this, it can be found out how the ancient Chinese ancestors used the way of thinking to regulate and restrict how different Chinese characters "distinguish" and "observe" each other in the process of the evolution from "real image" to "mental image".

\section{A. Pictograph}

Pictographs are words that describe the shape of a real object. Each word has a fixed pronunciation, which is already a true word compared to a pictorial character without a fixed reading. "Hieroglyphics mean to draw things as they are and the strokes twist and turn with the shape of things. In ancient Chinese, 'sun' and 'moon' are written in this way."4 That is to say, the outline or characteristic parts of things are depicted in the way of imagery thinking in the process of "real image" illusion, which embodies the basic principle of imagery thinking mode, that is, the mental image of the integration of subjective will and external image. This is true for both single and combined pictographs.

The original pictographs are certainly not the work of Cang Jie alone. In the process of evolution from pictorial characters

Hegel: "Erster Teil der Enzyklopa die der philosophischen Wissenschaften: Wissenschaft der Logik", Commercial Press 1980 Edition, p. 37.

(Han Dynasty) Xu Shen: "Shuowen Jiezi · Narrative (Analytical Dictionary of Characters · Narrative)".

In six categories of Chinese characters, in fact, only the first four types of Chinese characters can better reflect the substantive meaning of the word-formation, so our analysis only simply refers to the first four types according to the relationship between the shape and the meaning of the characters.

(Han Dynasty) Xu Shen: "Shuowen Jiezi · Narrative (Analytica Dictionary of Characters · Narrative)". 
to carved characters, there may be a random process in which different individuals have different feelings. The "experimental" nature of this formal language is an important part of the Chinese character-building stage. But "the unification of the symbolic reference of characters is the need of life" ${ }^{5}$ and it must be necessary for someone to coordinate and collect these characters. According to the "real image" perception of "judging the similarities and differences of things by their innate senses, because people of the same nationality and feeling have the same innate sense of things" 6 , and the rules of "consent" are formed or formulated, so that the original Chinese characters can gradually develops leaded by the imagery thinking under the guidance of "experience" and "recognition" to make "why to show" and "how to show" become a permanent cultural behavior of "predecessors leaving something for later generations, and later generations knowing the ancient"7.

From the point of view of word-making method, pictographs can best reflect the original meaning of words, but it is impossible for all things in the world to be imagined to be drawn in the way that "strokes twist and turn with appearance of the object $" 8$. Therefore, the aesthetic interest and intention in this kind of ideographic nature will surely melt and extend the past aesthetic experience and continue to experience the new formal language in the process of constantly emptying the "real image", enlarging the genealogical tree of Chinese literature.

\section{B. Indicative Characters}

There are concrete and abstract concepts. In abstract concept, it cannot be described in accordance with the real image. In other words, the outline or characteristic part of things cannot be drawn to create Chinese characters. So, indicative characters become a kind of Chinese characterbuilding method which expresses more abstract meanings by abstract symbols (dots and strokes). "As for indicative characters, we can know them once we see them and get their meaning after observing the top part and the bottom part" That is to say, they point out the characteristics of things by imagery thinking and have already had the abstract meaning. Among them, some indicative characters are composed of pure symbols, such as the characters of up and down structure; some are compound indicative symbols which add indicative symbols on the basis of pictographs to show the intention of word formation.

The character-making process of indicative characters has not only used imagery thinking, but also the holistic thinking. It means we cannot "turn upside down" or "put the cart before the horse". Duan Shiyu, a modern literary researcher, once

Zhang Xiaomang "On the History of the Principles of

Argumentation in Pre-Qin Dynasty", Renmin University of China Press 1966 edition, p. 69

6 Xunz Name Correction.

(Han Dynasty) Xu Shen: "Shuowen Jiezi Narrative (Analytical Dictionary of Characters Narrative)"

There are 9353 characters in Analytical Dictionary of Characters, including 364 pictographs, accounting for only $5 \%$.

(Han) Xu Shen: Shuowen Jiezi Narrative. believed that the negative image, the positive image, the intersection image and the mutual root image of Yin and Yang $^{10}$ in the formation process of Chinese characters should embody this holistic image thinking. Zhang Jiebin, a doctor of Ming Dynasty, said that the philosophy of the unity of opposites between Yin and Yang in medicine, "Yin roots in Yang, Yang roots in Yin, Yin and Yang converge, and everything is born... Yin and Yang root from each other and need each other and are inseparable. Without yang, Yin cannot live. Without yin, Yang cannot change" $" 11$. The principle is also reflected in the formation of Chinese characters. Though we can recognize indicative characters and get the meaning after observation, the indicative scope of indicative characters is very mall ${ }^{12}$. The images formed in the practice of life cannot be amended according to the experience of life, and are continuing to be abstracted in the experimental formal language.

\section{Associative Compound Characters}

“会意者，比类合谊，以见指挥，武信是也”. 13“比” means merge “谊” means meaning; “见” means “produce”; “挥” means "develop". It means that merges two or more associative characters and produce new meaning from the comparison of previous characters. The abstract meaning of “拼义” has been further developed. Takes “武” and “信” as examples.

The image of “武” is 证. The bottom part is “止”, and the top part is “划”. It means that a person carries a weapon ${ }^{14}$. The original meaning of "止" is foot. “脚不前行” means “stop", so “止” is extended to the meaning of “stop". “文” is opposite to “武”, so put “止” and “戈” together and produce “武”, 15. The image of “信” is 读. It means "honest”, and has two parts “人” and “言”16. “人” is the most noble in the world"17. “人” is the owner of all things on earth"18. Put “人” and “言” together and produce “信”. It is extended to the meaning of being honest to others. "Am I trustworthy to my friends?"19 It extends to the meanings of "trustworthy", "believe" and "pledge" from the meanings of "honest".

There are coessential indicative characters and variant indicative characters. They are all integrated with the methodological significance of imagery thinking. The merging meaning of subjective willingness and external image has embodied the unity of thinking and objective things, and the unity with the original meaning of character. The basis and significance of associative compound character lie in proximity association or relational association. Proximity

See Duan Shiyu, Ancient Chinese Philosophical Thoughts in

Chinese Characters, Xinjiang People's Publishing House, 2006, Chapter $1 \sim 4$ (Ming) Zhang Jiebin: Lei Jing.

There are only 129 indicative characters in Shuowen Jiezi. Shuowen Jiezi Narrative.

Tang Kejing, Modern Explanation of Shuowen Jiezi, Yuelu Bookstore, 1997, P 1807.

Zuo Zhuan 12ed Year of Xuan Gong.

Shuowen Jiezi Speech.

Shuowen Jiezi Human.

Shu Taishi (I).

The Analects of Confucius · Learning. 
association refers to thinking from one thing to another related. It is based on the proximity of the related things or some connection in time and space, while the association of relations originates from the causal relationship between the things.

In the development and evolution of hieroglyphic character, indicative character and associative compound character, various experimental open attitudes have fundamentally shaken the word-building idea that takes the visual reality of "Yuen Tian Guan" as solo purpose. In the experiments of meaning extension, can "the generalized image" make vivid intuition and concreteness indicate "image" after eliminating "imagery thinking"? Although there are 1267 ideographic characters in Shuowen Jiezi, they are still not enough for use. The need of reality is doomed to open up a broader experimental field. Under the regulation of imagery thinking, pictophonetic characters naturally come onto the stage of history.

\section{Phonogram}

Phonograms comprise the semantic radical that represents the meaning, and the phonetic radical that represents the sound, having the strongest ability in word formation. "Phonogram is formed through semantic radical, the meaning of which relates to things to be expressed, and phonetic radical, the pronunciation of which is the same as or similar to that of the new word, such as 江 and 河 in Chinese." ${ }^{20}$ Namely, "The Chinese character 江 relates to water, and its pronunciation is the same as I in old Chinese phonology (jiang)" ${ }^{21}$; "The Chinese character 河 relates to water, and its pronunciation is the same as 可 in old Chinese phonology (he)" ${ }^{\text {,2 }}$. Shuowen Jiezi has collected 9,353 characters, more than 80 percent of which are phonograms. All the abstract concepts and new Chinese vocabularies in language can become new characters through ideogram and phonetic element. For example, among the characters in the periodic table of elements, except for "mercury", the rest of the metallic elements all use the radical of "金”; all the non-metallic elements use the radical of “石”; except for "bromine", the rest of the gas elements all use the radical of “气”. It has proved:

First, the ideographic thinking embodies on "understanding the meaning" via ideogram. In Shuowen Jiezi, among the 540 radicals "from - to 亥", the relationship between each radical and the group of characters subordinate to it is the generic relationship of "A belonging to $\mathrm{B}$ is subordinate to $\mathrm{B}$ " or " $\mathrm{A}$ belonging to $\mathrm{B}$ is within the category of $\mathrm{B}$ ". With the normative requirement, it has presented the similar association in the logic-cognition way is guided through "understanding the meaning". That is to say, we can affirm things have identity or similarity according to their similarities on form or property. As the saying goes, "One should recognize half of a character to see whether he recognizes it", is showing the significance of distinguishing the "category" according to its radical. The ideogram of a phonogram is not completely equal to the original meaning, but a close relationship exists between the original meaning and ideogram. It has derived the logic-

20 Shuowen Jiezi, Narrative

21 Shuowen Jiezi, Radical 85

22 Shuowen Jiezi, Radical 85 cognition way of ideographic thinking methodology for us to learn and explain Chinese characters and know its extended meaning through the original meaning. For example, in the group of characters of “赴趋赶越超”, although the pronunciations of them are different, we can learn they relate to behaviors of walking and running of people according to the same radical “走” $(\underset{x}{\star})^{23}$. A further example, in the group of characters of “阈域蜮棫罭惐淢琙緎睵”, their pronunciations are the same, but we still can learn the category signified by each character according to the different radicals.

On the basis of the embodiment of ideographic thinking on the "understanding of meaning" and "sound discrimination" of phonogram, when the genealogical tree of Chinese characters grows and derives continuously, the category consciousness of "understanding of meaning" and "sound discrimination" has been strengthened obviously and ceaselessly, further consolidating the ideographic property of the great word formation function of Chinese characters. It is the norm that comes from living practice and the result concluded via groupthink. We can even say following the norm in the process of creating, explaining and recognizing Chinese characters means observing the powerful confinement of norm under the category consciousness of the ideographic thinking. It has formed an unvarying life experience through "the abidance by the rules is a practice" ${ }^{, 24}$ said by Wittgenstein.

In a word, the normative effect of the ideographic thinking in the process of forming Chinese characters has unceasingly derived tremendous new characters through the experience of "category consciousness", "the feeling and impression of human sense for the same category of things are the same". The similarity of portrait and gene exists within the same family. This is the secret of ideographic and productive Chinese characters.

\section{BASIS FOR THE FUNCTION OF IDEOGRAPHIC THINKING NORM}

\section{A. Historical Inevitability}

In the art of word formation in Chinese characters, ancestors followed a principle all the time, namely how to consistently express the cognitive freedom and will freedom of the soul through the change of form, pronunciation and meaning in the process of word formation. Undoubtedly, it is restricted by some inevitability.

Shuowen Jiezi has analyzed and classified the form and structure of seal character and summarized 540 radicals "from - to 亥" and classified different characters via the mark that "A belonging to B is subordinate to B", and indicated the deterministic criteria of classification respectively. The cognitive means of "treating respectively and classifying according to the category instead of mixing" is determined by the way of taking the same and differentiating the different in

\footnotetext{
23 "Running involves the bending of legs. Those belonging to running are subordinate to walking. Xu Kai says, the feet bend when people run, so it is subordinate to bending". Shuowen Jiezi, Radical156.

24 Wittgenstein, L..Philosophical Investigations. G.E.M Anscombe(trans). 2ed. Oxford: Basil Blackwell Ltd, 1958, p.81
} 
the "analogy" thinking method that has based on the ideographic thinking since the pre-Qin period. It has enabled us to extract genetic factors in the gene pool continuously according to the guidance of the ideographic thinking in the process of recognizing, explaining and using characters, then guaranteed the selection and stability of "tonal discrimination" and "understanding meaning" and shortened the differentiation process of "tonal discrimination" and "understanding meaning". Thus, under the norm of ideographic thinking, Chinese characters have become "the unique visual characters" continued, stored and used in the world through the guidance of "Pinyi Theory".

\section{B. Mutual Echoing of Production Object and Production Subject}

The structure of Chinese characters has not exceeded the stage of ideographic characters so far. Some new network languages appear continuously with the development of network, but they still follow the norm of ideographic thinking. For example, the character “雷” is originally a noun which means thunder, but it has the function and characteristic of verb or adjective in network language, means some unexpected people or things bring a strong impact, or people are shocked enormously by it. Another example, the character “圆” (with the pronunciation of jiong) means the panes stagger and are bright, but people use it to express depression, sorrow and helplessness by virtue of its character pattern and pronunciation in the network language. Besides, accompanied by the character “雷”, it was diffused into other media through network media and once became the popular word of China in 2008. Some hot words on the Internet such as “雷人” (shocking) and “宅男” (homebody) are included in the sixth edition of Modern Chinese Dictionary revised and issued in 2012.

It is also the logic-cognitive result of ideographic thinking of "taking the words too literally" only from the perspectives of the meaning of network language and the change of the meaning of characters existing. The result still saturates the origin of ideographic thinking, which plays the constant and stable role of traditional thinking methodology in guidance and has proved the celebrated dictum of Marx, "Art objects create the public that understand art and appreciate beauty, so do other products. Therefore, production produces objects for subjects, at the same time it produces subjects for objects". ${ }^{25}$ For example, during September and October in 2013, the Chinese Character Dictation Contest was held by CCTV. The word “铁床” (miller) was examined and the word is explained as "a kind of machinery". After hearing it and thinking for a while, contestants wrote down “石 (on the left) 先 (on the right)" 床. The thinking path may be: Most vocabularies examined previously are ancient vocabularies, so is this word. Ancient machineries generally take the radical of “石”, so does this character. If he knew it is a modern machine tool, maybe he would have another thinking path and wrote down “铣” correctly.

\footnotetext{
25 Marx Engels Selected Works (Volume 2), edition 1972 of People's
} Publishing House, p.95

\section{THE UNIFICATION AND REASONING CONSCIOUSNESS OF SEMANTICS AND PRAGMATICS OF CHINESE CHARACTERS}

If we continue to deduce on the basis of the beforementioned paper, we can also find that the vividness, intuition and concreteness of ideographic means of Chinese characters in the process of Chinese characters' word-making, worddeciphering and word-using. In the constant verification of signifier and designatum and under the constant mutual reflection of the production object and the production subject, the logical thought and method of analogy in the future have been laid a solid literary foundation by the way of the "image" of the "signifier" that classifies the intention to "image" refers to the "image" of the "referred to". From the developed origin of Chinese characters, it shows the spirit of rectification of name under the unification of semantics and pragmatics of Chinese characters.

\section{A. Spirit of Rectification of Name Under the Unification of Semantics and Pragmatics}

The ideographic characteristics of Chinese characters determine the purpose of Chinese character construction in order to determine the literal meaning of Chinese characters. In the pre-Qin period, the characters were called "name", and the unity of the reasonable definition (semantics) and appropriate use (pragmatics) of the literal meaning of Chinese characters was called "rectification of name". According to Morris's theory of semiotics, the relationship between linguistic symbol and the objects they are talking about is semantics. The relationship between linguistic symbol and the way they are applied is pragmatics. ${ }^{26}$ From this point of view, the process of correcting Chinese characters includes not only the reasonable semantic explanation of "the image of things, the sage has the profound ability to see the world",27, but also the description of "the image is also the things"28; it also includes the stipulations under this kind of semantic explanation, "knowing more about the names of birds, animals, plants and trees" and "the names of appropriate pragmatics are miscellaneous but not overwhelming" 29 . Thus, in the process of effective communication and communication of information dissemination, "highlight the past and look at the future, while slightly elucidate and silent. Open (juxtaposition) and distinguish between the name and the object, the severe advice and deducible word is enough. Its name is also small, its classification is large, its purpose is far-reaching, its words is cultural, its speech and songs and its matter wantonly and hidden"30, truly achieve "access to knowledge" and "the ratio of knowledge to meaning". 31

From the source of the occurrence of Chinese characters, the "discrete name" ${ }^{32}$ is said by Xuncius who rectifies the name of one hundred things in the Three Kings and Five

\footnotetext{
26 Please refer to Morris: Anzeichen, Language and Behavior, Shanghai People's Publishing House 2011 edition.

27 Yizhuan First copulative diction

28 Yizhuan Second copulative diction

29 Yizhuan Second copulative diction

30 Yizhuan Second copulative diction

31 The Book of Rites

32 Xuncius $\cdot$ Rectification of name.
} 
Emperors. In the stage, there should be differences in the subject of cognition, so that there is certain arbitrariness in the society that "name without solid appropriate" and "name without solid reality", but the problem of rectification of name obviously needs to consolidate the understanding by the certainty of the name. As a result, in order to "when the name is added to all things, because of from the summer of as a folk song showed music stage, the hometown of the distant custom is the same" ${ }^{33}$, it is necessary to carry out the stipulations of an agreement with the public understanding of collective thinking, so as to ensure the effectiveness in the process of information dissemination. Therefore, there is such thing as "the name is not suitable, and the life is about to be agreed. It is appropriate to agree on the customary principle. The name is not solid, about the real life; the customary name is the real name" ${ }^{34}$. The customary process is a process of agreeing on "consensus" and obeying it. The standard consciousness of imagery thinking should be produced in the process of manufacturing "discrete name".

As mentioned above, in the historical process of Chinese characters continual production, the standard consciousness of imagery thinking and its ethical tendency have their longlasting historical and cultural basis of "rectification of name to be correct the government" and "rectification of name entity to be benefit the world in the unification of the semantic interpretation of Chinese characters and the pragmatic operation. Taking the issue of rectification of name seriously is always a life attitude of the Chinese. According to the meaning theory of speech act of "the first clause of belief is the meaning of fame and righteousness" ${ }^{35}$ achieved by rectification of name, each person's political and ethical status and role in society are stipulated, and this ethical spirit is melted into Chinese traditional culture and is regarded as "the spirit of the Chinese people". ${ }^{36}$

\section{B. Implied Reasoning Consciousness Under Social Functions}

From the above, Chinese characters have become a "meaningful form" language with social function. From the perspective of general argument validity, the unity of semantics and pragmatics has the implicit reasoning consciousness under social function. This is because, in the linguistic philosophy and analytic philosophy, the question of "meaning" is a core and complex issue, and its representative research has meaning referential theory, meaning ideational theory, meaning use theory, truth conditional semantics, and meaning behavior theory formed from the perspectives of reference, concept, use, semantics, and behavior. Blanton, who is the representative of contemporary American linguistic philosophy, analyzes the meaning from the perspective of reasoning with the semantics of reasoning as the core content of its theory. ${ }^{37}$ There are two basic points: (1) the meaning of

\footnotetext{
33 Xuncius $\cdot$ Rectification of name.

34 Xuncius $\cdot$ Rectification of name.

35 Gu Hongming The Spirit of Chinese People Hainan Publishing House 2007 edition, p.43.

36 Refer to Gu Hongming, The Spirit of Chinese People Hainan Publishing House 2007 edition.

37 Blanton's Making It Explicit (1994) was called "a milestone in theoretical philosophy" by Habermas Habeimas, J... Form Kant to Hegel: On
}

language comes from the use of concepts, that is, reasoning; (2) the content of the concept plays a role in reasoning. Therefore, Blanton emphasizes the principle of "time priority", "doing" precedes "saying" and "knowing how" precedes "knowing what" ${ }^{38}$. According to Ludwig Wittgenstein, the norm should come from practice, and "obeying the rules is a practice." ${ }^{39}$ Blanton accepts this kind of pragmatic understanding of norms. In his view, the theory of conception is not an independent system. It relies on normative pragmatics about implicit norms. The unexplained initial concept in semantic theory must be placed in the pragmatic environment to be explained and stated. Therefore, Blanton believes that "semantics must conform to pragmatics." His inferential semantics is based on its normative pragmatics, the meaning of linguistic expression and the content of the intentional state of can only be finally explained in its actual use.

\section{CONCLUSION}

In summary, we believe that as a "unique visual text", the cultural essence of Chinese characters is the ideographical expression on the basis of "image" under the guidance of imagery thinking. If we look at the text reform that has begun since the end of the Qing Dynasty, although it is imperative to have historical inevitability, how to change it, we must think about the inheritance of tradition. Therefore, as for Chinese characters are simplified or simplified in Chinese characters for more than 100 years, it is reasonable to think about how to integrate the cultural inheritance in the process of making Chinese characters on the basis of convenience, rationality and universality.

Finally, I want to mention a wonderful thing that is hard to say. In the correct tonal discrimination of Chinese characters, Shuowen Jiezi uses the phonetic method - anti-cut method. This is a two-word spelling of the pronunciation of another word. The first character of Fanqie is the same the initial consonant of a Chinese syllable with the Fanqie word. The second character of Fanqie is the same the simple or compound vowel of a Chinese syllable and the tone with the Fanqie word. That is, the word is taken sound, and the next word is taken rhyme and tone. Most of the Chinese characters can be Fanqie in this way, and the Fanqie original or the finals can be expressed in Chinese Pinyin in the Modern Chinese Dictionary. Modern Chinese Pinyin comes from the Latin alphabet of the West. In the 1980s, due to the advent of the era of electronic computer networks, it was once claimed that China would always lag behind the times for reasons of writing. However, this alarmism has not appeared. Nowadays, various intelligent pinyin input methods have emerged, and computer display technology has bridged the differences between Chinese characters and pinyin. I am afraid that the ancients did not think in the process of making words that the Western dialect letters separated from them by a hundred thousand miles, after many years, actually came together with

Robert Brandom's Pragmatic Philosophy of Language .M. Cooke (trans). European Journal of Philosophy, 2000, p.322.

38 Brandom, R... Making It Explicit. Cambridge, Mass. Harvard University Press, 1994, p135-136.

39 Wittgenstein, L..Philosophical Investigations .G.E.M. Anscombe (trans). 2ed. Oxford: Basil Blackwell Ltd, 1958, p.81. 
the ideograms they created, and solved the Chinese people's a big problem that continued move toward new civilization. From this point of view, the Chinese text is really a "person who can walk a long way." In this sense, in October 2017, UNESCO announced that the Oracle project submitted by China was approved by the International Advisory Committee of the UNESCO World Memory Project and was selected as the "Memory of the World". It is also a kind of affirmation of Chinese character, the oldest and most youthful writing system. From the perspective of logic and culture, today we should reexamine the cultural essence of Chinese characters, and observe the logical methodology principles, aesthetic concepts, technical methods, cultural traditions, and humanistic spirit behind them, thus continuously enhancing our feelings to the significance of traditional thinking methodology and cultural identity.

\section{REFERENCES}

[1] Zhang Xiaomang "On the History of the Principles of Argumentation in Pre-Qin Dynasty”, Renmin University of China Press 1966 edition, p. 69.

[2] Wittgenstein,L, Philosophical Investigations. G.E.M. Anscombe(trans). 2ed. Oxford: Basil Blackwell Ltd, 1958, p.81

[3] Marx Engels Selected Works (Volume 2), edition 1972 of People's Publishing House, p.95.

[4] Gu Hongming, The Spirit of Chinese People Hainan Publishing House 2007 edition, p.43

[5] Brandom, R, Making It Explicit. Cambridge, Mass. Harvard University Press, 1994, p135-136

[6] Wittgenstein, L, Philosophical Investigations .G.E.M. Anscombe (trans). 2ed. Oxford: Basil Blackwell Ltd, 1958, p.81. 